\title{
Impact of influenza vaccination programmes among the elderly population on primary care, Portugal, Spain and the Netherlands: 2015/16 to 2017/18 influenza seasons
}

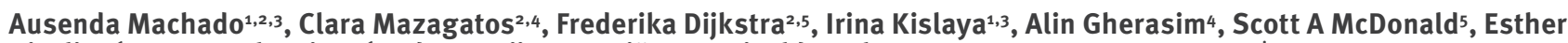

Kissling ${ }^{6}$, Marta Valenciano ${ }^{6}$, Adam Meijer ${ }^{5}$, Mariëtte Hooiveld7, Baltazar Nunes ${ }^{1,3}$, Amparo Larrauri $^{4}$

1. National Institute for Health Doutor Ricardo Jorge, Epidemiology department, Lisbon, Portugal

2. These authors contributed equally

3. NOVA National School of Public Health, Public Health Research Centre, Universidade NOVA de Lisboa, Lisbon, Portugal

4. National Centre of Epidemiology, Carlos III Health Institute, CIBER of Epidemiology and Public Health (CIBERESP), Madrid, Spain

5. National Institute for Public Health and the Environment (RIVM), Bilthoven, the Netherlands

6. Epidemiology department, Epiconcept, Paris, France

7. Nivel, Netherlands Institute for Health Services Research, Utrecht, the Netherlands

Correspondence: Ausenda Machado (ausenda.machado@insa.min-saude.pt)

Citation style for this article:

Machado Ausenda, Mazagatos Clara, Dijkstra Frederika, Kislaya Irina, Gherasim Alin, McDonald Scott A, Kissling Esther, Valenciano Marta, Meijer Adam, Hooiveld Mariëtte, Nunes Baltazar, Larrauri Amparo. Impact of influenza vaccination programmes among the elderly population on primary care, Portugal, Spain and the Netherlands: $2015 / 16$ to 2017/18 influenza seasons. Euro Surveill. 2019;24(45):pii=1900268. https://doi.org/10.2807/1560-7917.ES.2019.24.45.1900268

Background: To increase the acceptability of influenza vaccine, it is important to quantify the overall benefits of the vaccination programme. Aim: To assess the impact of influenza vaccination in Portugal, Spain and the Netherlands, we estimated the number of medically attended influenza-confirmed cases (MAICC) in primary care averted in the seasons $2015 / 16$ to $2017 / 18$ among those $\geq 65$ years. Methods: We used an ecological approach to estimate vaccination impact. We compared the number of observed MAICC (n) to the estimated number that would have occurred without the vaccination programme $(\mathrm{N})$. To estimate $\mathrm{N}$, we used: (i) MAICC estimated from influenza surveillance systems, (ii) vaccine coverage, (iii) pooled (sub)typespecific influenza vaccine effectiveness estimates for seasons $2015 / 16$ to $2017 / 18$, weighted by the proportion of virus circulation in each season and country. We estimated the number of MAICC averted (NAE) and the prevented fraction (PF) by the vaccination programme. Results: The annual average of NAE in the population $\geq 65$ years was 33,58 and 204 MAICC per 100,000 in Portugal, Spain and the Netherlands, respectively. On average, influenza vaccination prevented $10.7 \%, 10.9 \%$ and $14.2 \%$ of potential influenza MAICC each season in these countries. The lowest PF was in 2016/17 (4.9$6.1 \%$ ) with an NAE ranging from 24 to 69 per 100,000 . Conclusions: Our results suggest that influenza vaccination programmes reduced a substantial number of MAICC. Together with studies on hospitalisations and deaths averted by influenza vaccination programmes, this will contribute to the evaluation of the impact of vaccination strategies and strengthen public health communication.

\section{Background}

Influenza infections cause considerable morbidity and mortality [1,2], in particular among the elderly population 65 years and older. Vaccination is considered the most important public health intervention to reduce the incidence of seasonal influenza and its associated complications [3]. Following the World Health Organization recommendations [4], most European countries have a yearly influenza vaccination programme targeting, among others, individuals aged 65 years and older [5]. In most European Union (EU) countries, vaccine coverage (VC) in individuals in high-risk groups is below the target of $75 \%$ set by the EU Council [6].

To increase the acceptability of the influenza vaccine, it is important to assess the benefits of vaccination. Since 2008, influenza vaccine effectiveness (IVE) studies conducted every season in the EU suggest that the effectiveness of the vaccine is low to moderate in the elderly population $[7,8]$. These estimates provide useful information for scientists, but could be less comprehensible for the general public and for policymakers.

Estimating the impact of the influenza vaccination campaign focusing on the overall effect of the vaccine in the population has been an approach used by several countries [2,9-12]. Preaud et al. took a multicountry approach at European level [13]. In that study, the authors evaluated the public health and economic benefits of influenza vaccination, quantifying the prevented cases of influenza, hospitalisations and deaths in target groups for vaccination. They used countryspecific data, when available, and interpolated data 
TABLE 1

Country-specific influenza vaccination programmes and influenza surveillance systems, the Netherlands, Portugal and Spain, influenza seasons 2015/16-2017/18

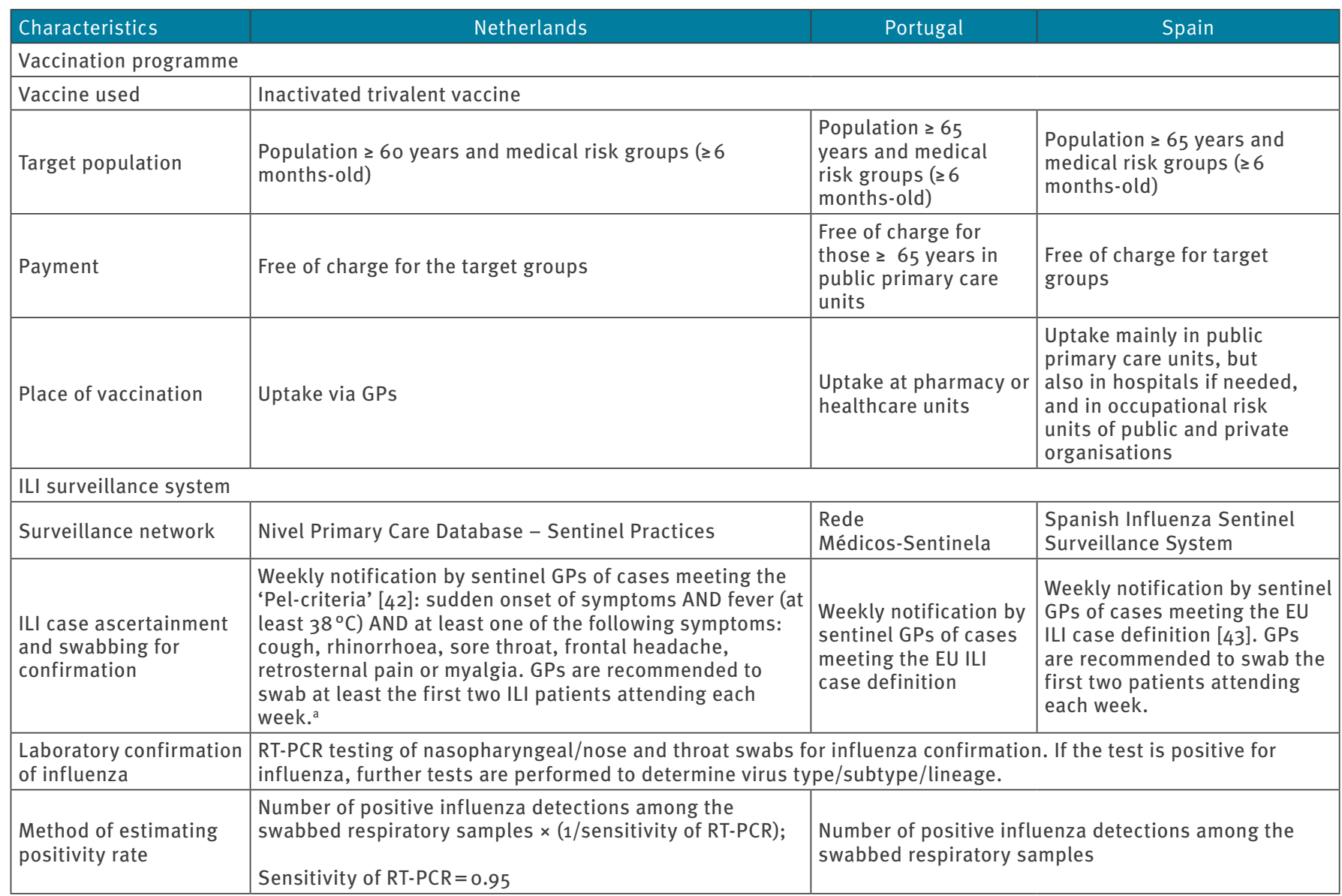

EU: European Union; GP: general practitioner; ILI: influenza-like illness.

a Patients $<65$ years of age consulting on Monday through Wednesday and all ILI patients 65 years and older during the whole week.

otherwise, that covered different seasons according to the different parameters. These authors quantified the differences in the number of influenza-confirmed associated events between the population exposed and the population not exposed to the vaccination programme using three parameters: IVE, VC and number of observed events. Impact was expressed as the number of influenza associated events averted by the influenza vaccination programme. These impact indicators to evaluate vaccine performance are easy to understand and to interpret.

To compare the number of averted events (NAE) in different countries with similar but not equivalent vaccination strategies, it is important to have not only a common approach but also harmonised parameter criteria. The lack of country-specific data limited the comparison of the impact of European influenza vaccination programmes [13]. Therefore, we developed a common protocol within the I-MOVE+ project [14] with a harmonised methodology that could measure, in different countries, the impact of the influenza vaccination programme. In this study, we aimed to assess the impact of the influenza vaccination programmes in Portugal, Spain and the Netherlands, by measuring the number of medically attended influenza-confirmed cases (MAICC) in primary care averted by vaccination, among the population aged 65 years and older, in three consecutive seasons (2015/16 to 2017/18). This was done by integrating existing estimates into new measures that may be more meaningful for public health policymakers and the public.

\section{Methods}

\section{Study design}

We developed an ecological study to estimate the number of medically attended influenza averted by the influenza vaccination programme.

We computed the number of averted events as:

$$
N A E=n \times \frac{V C \times I V E}{1-(V C \times I V E)}
$$


TABLE 2

Number of ILI, positivity rate and proportion of influenza (sub)types, MAICC, VC and VE among those aged $\geq 65$ years, Portugal, Spain and the Netherlands, influenza seasons 2015/16-2017/18

\begin{tabular}{|c|c|c|c|c|c|c|}
\hline & \multicolumn{2}{|c|}{$2015 / 16$} & \multicolumn{2}{|c|}{$2016 / 17$} & \multicolumn{2}{|c|}{$2017 / 18$} \\
\hline & $\mathrm{n}$ or $\%$ & $95 \% \mathrm{Cl}$ & $\mathrm{n}$ or $\%$ & $95 \% \mathrm{Cl}$ & $\mathrm{n}$ or $\%$ & $95 \% \mathrm{Cl}$ \\
\hline \multicolumn{7}{|l|}{ Portugal } \\
\hline ILI (n) & 9,161 & $6,656-12,297$ & 21,646 & $17,289-26,766$ & 12,366 & $9,340-16,057$ \\
\hline Positivity rate (\%) & 27.8 & $20.5-35.1$ & 47.4 & $40.2-54.5$ & 46.2 & $43.0-49.3$ \\
\hline MAICC (n) & 2,547 & $1,641-3,686$ & 10,261 & $7,673-13,087$ & 5,708 & $4,247-7,298$ \\
\hline VC (\%) & 50.1 & $42.1-58.1$ & 57.5 & $50.8-64.1$ & 60.8 & $55.5-65.9$ \\
\hline Subtype $A\left(\mathrm{H}_{1} \mathrm{~N}_{1}\right)$ pdmog (\%) & \multicolumn{2}{|r|}{90.4} & \multicolumn{2}{|r|}{0.2} & \multicolumn{2}{|c|}{20.0} \\
\hline Subtype $\mathrm{A}\left(\mathrm{H}_{3} \mathrm{~N}_{2}\right)(\%)$ & \multicolumn{2}{|r|}{1.3} & \multicolumn{2}{|r|}{99.6} & \multicolumn{2}{|c|}{14.0} \\
\hline Type B (\%) & \multicolumn{2}{|r|}{8.3} & \multicolumn{2}{|r|}{0.2} & \multicolumn{2}{|c|}{66.0} \\
\hline IVE (\%) & 40.6 & $22.6-58.6$ & 8.5 & -10.9 to 27.9 & 23.8 & $10.9-36.8$ \\
\hline \multicolumn{7}{|l|}{ Spain } \\
\hline ILI (n) & 53,534 & $49,994-57,199$ & 82,602 & $78,086-87,249$ & 102,839 & $97,785-107,959$ \\
\hline Positivity rate (\%) & 41.8 & $36.4-47.2$ & 47.8 & $42.8-52.8$ & 60.5 & $56.1-64.8$ \\
\hline MAICC (n) & 22,349 & $19,146-25,611$ & 39,422 & $34,874-44,206$ & 62,113 & $56,900-67,575$ \\
\hline VCa (\%) & \multicolumn{2}{|r|}{56.1} & \multicolumn{2}{|r|}{$55 \cdot 5$} & \multicolumn{2}{|c|}{55.7} \\
\hline Subtype $A\left(\mathrm{H}_{1} \mathrm{~N}_{1}\right)$ pdmog (\%) & \multicolumn{2}{|r|}{69.9} & \multicolumn{2}{|r|}{0.0} & \multicolumn{2}{|r|}{7.6} \\
\hline Subtype $\mathrm{A}\left(\mathrm{H}_{3} \mathrm{~N}_{2}\right)(\%)$ & \multicolumn{2}{|r|}{4.0} & \multicolumn{2}{|r|}{94.4} & \multicolumn{2}{|c|}{$25 \cdot 3$} \\
\hline Type B (\%) & \multicolumn{2}{|r|}{23.9} & \multicolumn{2}{|r|}{0.6} & \multicolumn{2}{|c|}{64.9} \\
\hline IVE (\%) & 34.0 & $18.5-48.4$ & 9.0 & -10.8 to 27.8 & 20.0 & $8.8-30.5$ \\
\hline \multicolumn{7}{|l|}{ Netherlands } \\
\hline ILI (n) & 73,250 & $63,890-83,290$ & 86,700 & $76,530-97,650$ & 96,300 & $86,120-106,900$ \\
\hline Positivity rateb (\%) & 34.9 & $26.3-44.8$ & 38.5 & $28.6-49.7$ & 67.2 & $58.2-77.0$ \\
\hline MAICC (n) & 25,900 & $15,510-37,740$ & 33,760 & $20,570-48,840$ & 65,120 & $48,100-80,770$ \\
\hline VC (\%) & 66.5 & $59.3-73.1$ & 62.9 & $56.1-69.2$ & 60.4 & $53.9-66.5$ \\
\hline Subtype $A\left(\mathrm{H}_{1} \mathrm{~N}_{1}\right)$ pdmog (\%) & \multicolumn{2}{|r|}{73.5} & \multicolumn{2}{|r|}{1.8} & \multicolumn{2}{|c|}{2.8} \\
\hline Subtype $\mathrm{A}\left(\mathrm{H}_{3} \mathrm{~N}_{2}\right)(\%)$ & \multicolumn{2}{|r|}{0.0} & & 92.9 & & 18.3 \\
\hline Type B (\%) & & 26.5 & & 5.4 & & 8.9 \\
\hline IVE (\%) & 37.1 & $21.7-52.5$ & 9.7 & -8.4 to 27.8 & 19.5 & $4.7-34.4$ \\
\hline
\end{tabular}

$\mathrm{Cl}$ : confidence interval; ILI: influenza-like illness; IVE: influenza vaccine effectiveness; MAICC: medically attended influenza-confirmed cases; VC: vaccine coverage.

${ }^{a} 95 \% \mathrm{Cl}$ not available. VC in Spain calculated from administrative data, dividing the number of administered vaccine doses by the population.

${ }^{\mathrm{b}}$ Adjusted for test sensitivity.

$\mathrm{NAE}=\mathrm{n} \times \mathrm{VC} \times \mathrm{IVE} 1-(\mathrm{VC} \times \mathrm{IVE}) \mathrm{NAE}=\mathrm{n} \times \mathrm{VC} \times \mathrm{IVE} 1-(\mathrm{VC} \times \mathrm{IVE})$ where $n$ is the number of observed MAICC. To enable comparison between countries, NAE was also presented per 100,000 population. We estimated the prevented fraction as $\mathrm{PF}=\mathrm{NAE} /(\mathrm{n}+\mathrm{NAE})$. In addition, we calculated number needed to vaccinate (NNV) to prevent one MAICC, using methodology described in the Supplementary material.

\section{Input data}

Influenza vaccination strategy

In the seasons $2015 / 16$ to $2017 / 18$, trivalent inactivated influenza vaccines were available for the population 65 years and older in the three countries. All countries had a national seasonal influenza vaccination programme in place and influenza vaccination was recommended for high-risk individuals (older age groups and individuals with chronic medical conditions) (Table 1). Seasonal influenza vaccination was recommended free of charge to individualsolder than 60 years in the Netherlands, older than 60 or 65 years (depending on the region) in Spain, and 65 years and older in Portugal.

Medically attended influenza-confirmed cases at primary care level

To estimate the number of observed MAICC, we combined epidemiological and virological data routinely collected by country-specific sentinel influenza surveillance systems (Table 1) during the surveillance epidemic period (week 40 to week 20). For Portugal, end-of-season cumulative ILI incidence rates in the seasons $2015 / 16$ to $2017 / 18$ were adjusted by end-ofseason influenza positivity rate in the respective season and extrapolated to the national population aged 65 years and older. For Spain, weekly ILI and positivity rate were used to obtain ILI and number of positive cases. For the Netherlands, the observed number of 
TABLE 3

Seasonal average, number and rates of MAICC events averted among those aged $\geq 65$ years, by season, Portugal, Spain and the Netherlands, influenza seasons 2015/16-2017/18

\begin{tabular}{|c|c|c|c|c|c|}
\hline Country & Indicator & $2015 / 16$ & $2016 / 17^{a}$ & $2017 / 18$ & Average \\
\hline \multirow{3}{*}{ Portugal } & $\operatorname{NAE}(95 \% \mathrm{Cl})$ & $650(265-1,162)$ & $527(-746$ to 1,876$)$ & $967(316-1,701)$ & $715(215-1,246)$ \\
\hline & Rate NAE/105 $(95 \% \mathrm{Cl})$ & $30(13-52)$ & $24(-35$ to 85$)$ & $44(15-77)$ & $33(9.9-57.3)$ \\
\hline & $\mathrm{PF}$ in $\%(95 \% \mathrm{Cl})$ & $20.3(10.7-28.4)$ & $4.9(-7.9$ to 15.1$)$ & $14.5(5.4-21.9)$ & $10.7(3.3-16.4)$ \\
\hline \multirow{3}{*}{ Spain } & $\operatorname{NAE}(95 \% \mathrm{Cl})$ & $5,268(2,453-8,224)$ & $\begin{array}{c}2,073(-2,657 \text { to } \\
6,758)\end{array}$ & $\begin{array}{c}7,787 \\
(2,891-12,648)\end{array}$ & $5,042(2,602-7,500)$ \\
\hline & Rate NAE/105 (95\% Cl) & $61(29-96)$ & $24(-30$ to 78$)$ & $88(33-143)$ & $58(30-86)$ \\
\hline & $\mathrm{PF}$ in $\%(95 \% \mathrm{Cl})$ & $19.1(10.1-26.4)$ & $5.0(-7.1$ to 14.5$)$ & $11.1(4.4-16.9)$ & $10.9(5.9-15.3)$ \\
\hline \multirow{3}{*}{ Netherlands } & NAE $(95 \% \mathrm{Cl})$ & $8,483(3,396-16,255)$ & $\begin{array}{c}2,194(-2,141 \text { to } \\
7,524)\end{array}$ & $\begin{array}{c}8,694 \\
(1,158-17,487) \\
\end{array}$ & $6,457(2,310-12,013)$ \\
\hline & Rate NAE/105 (95\% Cl) & $275(110-527)$ & $69(-68$ to 238$)$ & $268(36-540)$ & $204(74-380)$ \\
\hline & $\mathrm{PF}$ in $\%(95 \% \mathrm{Cl})$ & $24.7(12.7-34.6)$ & $6.1(-6.7$ to 16.8$)$ & $11.8(1.8-20.3)$ & $14.2(5.2-21.5)$ \\
\hline
\end{tabular}

$\mathrm{CI}$ : confidence interval; MAICC: medically attended influenza-confirmed cases; NAE: Number of averted MAICC events; PF: prevented fraction.

${ }^{a}$ Negative lower bounds of $95 \% \mathrm{CI}$ for NAE, averted rate and PF in 2016/17 season reflect the uncertainty around the point estimates and should not be interpreted as 'negative impact'.

Parameter point estimates from Table 2 were used to calculate the point estimates of NAE, averted rate and PF.

MAICC was estimated using a component of an evidence synthesis modelling framework that integrates data on ILI incidence, influenza positivity rate and sensitivity of virological testing and is routinely used for estimating seasonal influenza incidence in the Netherlands [15]. Virus shedding peaks around 1 to 2 days after onset of symptoms, after which - for healthy persons - it usually declines to undetectable levels 7 days after onset of symptoms [15]. Therefore, we restricted the laboratory diagnostic data from the Netherlands to those patients diagnosed with ILI from whom a specimen had been collected not more than 7 days after symptom onset. For Spain and Portugal this restriction is not applied in the surveillance system. In both countries, the great majority of ILI patients recruited by sentinel general practitioners (GPs) were swabbed within the first 7 days after onset of symptoms (>93\%). ILI data were obtained from national sentinel GP networks (the Dutch Nivel Primary Care Database, the Spanish Influenza Sentinel Surveillance System (SISSS) and the Portuguese Rede Médicos-Sentinela [16-18] (Table 1).

\section{Vaccine coverage}

In the Netherlands, influenza VC in the population aged 65 and older was estimated using pseudo-anonymised data from electronic medical files of GPs participating in the Nivel Primary Care Database [19]. The VC point estimate as well as 95\% confidence intervals $(\mathrm{Cl})$ were computed using multilevel logistic regression, taking into account the clustering of patients in GP practices [19]. In Spain, VC in the population aged 65 and older was provided by the Spanish Ministry of Health, based on administrative data of the number of doses of influenza vaccine administered [20]. In Portugal, VC was estimated using data from the 2015/16 and 2016/17 waves of a population-based telephone survey among the non-institutionalised population in mainland Portugal [21].
Vaccine effectiveness

We used the IVE among those aged 65 years and older estimated in the I-MOVE+multicentre primary carebased test-negative design case-control study [22-24]. We pooled the VE of three seasons (2015/16-2017/18) (Supplementary Table S1) and weighted the (sub)typespecific VE by the proportion of influenza (sub)type detected in primary care settings in each country.

\section{Uncertainty estimation}

To estimate the $95 \% \mathrm{CI}$ for NAE and PF, we used a probabilistic Monte Carlo approach. We constructed empirical distributions for influenza-associated outcomes, positivity rate, IVE and VC and used the 2.5 and 97.5 percentiles of these empirical distributions to compute the $95 \% \mathrm{Cl}$ for NAE and PF. All analyses were performed using STATA software.

\section{Ethical statement}

The study was based on aggregated data obtained from official statistics, influenza surveillance systems and epidemiological studies (IVE studies) with scientific protocols approved by the national ethical committees of the three involved countries. Given the ecological nature of the study, no additional ethical approval was required.

\section{Results}

\section{Input data}

Medically attended influenza-confirmed cases at primary care level

In seasons 2015/16 and 2016/17, ILI epidemics occurred in similar periods in the three countries. In the 2017/18 season, a longer ILI epidemic was observed in the Netherlands (Supplementary Figure S1). 
In all countries, the largest proportion of viruses detected in the sentinel networks were influenza $\mathrm{A}\left(\mathrm{H}_{1} \mathrm{~N}_{1}\right)$ pdmog in $2015 / 16$, influenza $\mathrm{A}\left(\mathrm{H}_{3} \mathrm{~N}_{2}\right)$ in 2016/17 and influenza B in 2017/18 (Table 2). The highest number of MAICC occurred in 2016/17 and 2017/18.

Vaccine coverage

In the study period, VC in the population aged 65 years and older ranged between $50.1 \%$ (Portugal) and $66.5 \%$ (the Netherlands) (Table 2). The VC increased in Portugal (from $50.1 \%$ in $2015 / 16$ to $60.8 \%$ in $2017 / 18$ ), decreased in the Netherlands (from $66.5 \%$ in 2015/16 to $60.4 \%$ in $2017 / 18$ ) and remained similar in Spain.

\section{Influenza vaccine effectiveness}

The IVE estimates ranged between $34.0 \%$ and $40.6 \%$ in $2015 / 16,8.5 \%$ and $9.7 \%$ in $2016 / 17$, and $19.5 \%$ and $23.8 \%$ in $2017 / 18$ (Table 2). In the $2016 / 17$ season, when influenza $A\left(\mathrm{H}_{3} \mathrm{~N}_{2}\right)$ virus was circulating in all countries, the IVE among the population 65 years and older was notably lower compared with other seasons.

Impact of influenza vaccination in the prevention of medically attended influenzaconfirmed cases

Number of averted events

Among those aged 65 years and older, influenza vaccination prevented an average per season of 715 MAICC in Portugal, 5,042 in Spain, and 6,457 in the Netherlands (Table 3). In Portugal, Spain and the Netherlands, the NAE per 100,000 population 65 years and older was 30,61 and 275 in the $2015 / 16$ season, 24,24 and 69 in the $2016 / 17$ season and 44,88 and 268 in the $2017 / 18$ season, respectively. The three seasons' NAE rate was 204 cases per 100,000 in the Netherlands, 58 cases per 100,000 in Spain and 33 cases per 100,000 in Portugal (Table 3).

Prevented fraction and number needed to vaccinate The seasonal average estimates of MAICC prevented fractions were similar for the three countries. The PF ranged between $19.1 \%$ and $24.7 \%$, in the $2015 / 16$ season, between $4.9 \%$ and $6.1 \%$ in $2016 / 17$ and between $11.1 \%$ and $14.5 \%$ in $2017 / 18$ (Table 3 ).

As expected, the number needed to vaccinate to prevent one MAICC followed the pattern observed for NAE, with the lowest NNV values for season 2017/18 and the highest for season 2016/17 in all countries (Supplementary Table S2).

\section{Discussion}

Our results suggest that during the $2015 / 16$ to $2017 / 18$ seasons, the influenza vaccination programmes in Portugal, Spain and the Netherlands had a sustained and positive impact on primary care MAICC in the population aged 65 years and older. The influenza vaccination programmes prevented an annual average of 33-204 primary care MAICC per 100,000 and $10.7-14.2 \%$ of potential MAICC that would have occurred without vaccination programme.

The impact of the influenza vaccination programmes varied across the influenza seasons. We obtained MAICC prevented fractions in the $2015 / 16$ season of $19.1-24.7 \%$, comparable to a study conducted in the United States (US) in 2013 that reported an average prevented fraction of $18.4 \%$ over six seasons [11].

We observed the lowest NAE during the 2016/17 season, when influenza $\mathrm{A}\left(\mathrm{H}_{3} \mathrm{~N}_{2}\right)$ dominated in all countries. Given that VC did not vary considerably in the three seasons, the main drivers for the differences in season-specific NAE would be the number of MAICC and the IVE estimates. Seasons with dominant influenza $A\left(\mathrm{H}_{3} \mathrm{~N}_{2}\right)$ circulation are reported to produce a high influenza burden in the elderly population [25], and often a limited IVE against subtype $\mathrm{A}\left(\mathrm{H}_{3} \mathrm{~N}_{2}\right)[26,27]$. In $2016 / 17$, the IVE was below $10 \%$ in the three countries. Despite this low protection, our results suggest that influenza vaccination programmes averted 24, 24 and 69 primary care MAICC per 100,000 population among those aged 65 years and older in Portugal, Spain and the Netherlands, respectively. This is consistent with other studies where, even in seasons with low vaccine effectiveness, the vaccination programme was able to avert influenza consultations, hospitalisations and deaths $[2,9,28]$. Particularly for the influenza vaccine with often limited effectiveness $[26,29]$, such a message might illustrate considerable vaccine impact at population level, even when the vaccine effect at individual level is suboptimal.

Also the prevented proportion of primary care MAICC was the lowest in the $2016 / 17$ season, namely $4.9 \%$ in Portugal, $5.0 \%$ in Spain and $6.1 \%$ in the Netherlands. A similar low PF (7-11\%) was estimated in the US for seasons with predominant influenza $A\left(\mathrm{H}_{3} \mathrm{~N}_{2}\right)$ circulation $[30,31]$. The NAE results also differed by country, with Spain and Portugal both showing lower estimates than the Netherlands. As NAE is a linear function of primary care MAICC, a large difference in MAICC across countries or across seasons will lead to a large NAE difference.

In this study, we estimated the MAICC using primary care surveillance data. Potential explanations for the observed differences could be (i) the influenza positivity rate, (ii) the methods of the surveillance system, e.g. the case definition used to recruit ILI cases from the health system and (iii) the healthcare seeking behaviour.

The percentage of positive influenza cases among all tested varies between seasons and between countries, depending mainly on the (sub)type of the circulating virus and the sentinel GPs' swabbing practice. The positivity pattern in the three countries was similar, with the highest positivity rate in the $2017 / 18$ season, when influenza B virus accounted for more than $65 \%$. 
The opposite was observed in 2016/17, when almost all isolates were influenza $A\left(\mathrm{H}_{3} \mathrm{~N}_{2}\right)$. This subtype is more frequent among older adults in whom ILI rates are generally lower [32], which could explain a lower positivity rate.

Differences among countries can be derived from different (sub)type distributions in the circulating virus and also from different real swabbing practices between countries, even if, as in our study, systematic swabbing is established in the three countries. Another source of differences is the correction of the Dutch positivity rate for the RT-PCR sensitivity. Given that the RT-PCR sensitivity rate used was $95 \%$, this would represent a systematic relative increase of $5.3 \%(1 / 0.95)$ in the Dutch positivity rates. This small increase does not explain the different NAE rate between countries.

Differences in national surveillance protocols may also play a role, e.g. the ILI case definition: In the Netherlands, the ILI case definition requires a fever $\geq 38^{\circ} \mathrm{C}$, while the EU ILI case definition used in Spain and Portugal only requires 'fever or feverishness'. Fever may be associated with more severe illness and with a higher likelihood of healthcare use $[33,34]$. In addition, the identification of ILI patients and the selection of patients for swabbing rely on the GP's criteria, which may be influenced by how influenza surveillance has been done historically in their country, regardless of the ILI case definition used. Another important factor contributing to the different MAICC is probably the healthcare seeking behaviour in the age group 65 years and older. The use of primary healthcare has been described to be the highest in the Netherlands among the three countries [35]. In Portugal, the general population often uses emergency rooms at hospitals to treat acute illness [36], while in Spain and the Netherlands, the GP is the first point of call for an influenza consultation [37,38].

This study has limitations. One is the approach used to measure the impact assuming no indirect effect, i.e. no herd protection conferred by the vaccinated population to the non-vaccinated population. Dynamic model simulations have demonstrated that the indirect effect may not be negligible, particularly regarding the effect of vaccinating children on the adult population $[39,40]$. A meta-analysis revealed that influenza vaccination in children may result in herd protection for the community-dwelling elderly population against influenza-associated mortality [41]. However, to observe this herd protection in the population aged 65 years and older, a minimum VC of $20 \%$ is needed in children [39]. In our study, the indirect effect may be small since there is no overall vaccination recommendation for the younger population in any of the three countries and VC in adults younger than 65 years is presumably low. In Portugal for instance, the VC in all three seasons was below $5 \%$ in the $0-15$ year-olds and between $7 \%$ and $18 \%$ in adults younger than 65 years [21]. In the Netherlands VC was $10 \%$ for the total population aged 18-64 years in the 2017/18 season [19]. However, non-vaccinated elderly people may still benefit from vaccination of younger age groups, particularly in settings with high VC in those 65 years and older [39]. As such, the NAE estimated in this study may be underestimated and the real impact of the vaccination programme could be even higher.

Another component that is not accounted for in our approach is that part of the estimated impact outcome measures may be attributable to previously acquired immunity, either through vaccination or natural infection. Our method does not allow us to distinguish which proportion among the prevented fraction is due to previous immunity and which is due to the current seasonal vaccination.

Another limitation to be acknowledged are the different ILI definitions and sources to estimate the VC, where some countries used population-based surveys, others GP surveys or administrative registries. In Portugal and the Netherlands, only the VC of community-dwelling elderly population is captured.

In Spain, regional administrative registries were used to calculate the national influenza VC. In the majority of the regions, the registry includes vaccines administered in both the public and the private sector. Only a few small regions report only vaccines administered in the public sector, therefore, we expect that influenza VC used reflected the VC in the population.

The study has several noteworthy strengths. Firstly, we used population-based surveillance data, so that the study can be replicated in several seasons and the results generalised for the population. Secondly, the IVE estimates derived from European pooled estimates were specific to the influenza (sub)type and adjusted to virus circulation in the country. This procedure not only allows us to obtain more precise estimates but also increases the robustness of the NAE results. Finally, we used country-specific data for all three countries individually, with harmonised analytical methods and definitions, allowing direct inter-country comparison.

\section{Conclusion}

The development of the common protocol resulted in a comparable population-based indicator of the impact of influenza vaccination programmes in the three countries. This can benefit existing influenza surveillance systems which already capture the annual influenza burden through national surveillance as well as estimation of the IVE through the I-MOVE network. Furthermore, by including severe influenza outcomes in future impact estimations, such as hospitalisations and deaths related to influenza, we will be able to provide a comprehensive view of the annual burden of influenza-related morbidity and mortality averted by vaccination. 
These results are important to support public health communication aiming to increase VC in high-risk groups. Influenza vaccination programmes can gain impact by increasing VC and/or IVE. Quantifying the benefit of annual vaccinations through estimates of their impact may contribute to this public health challenge, which could be a key message to the general public and decision makers, particularly in seasons with low vaccine effectiveness.

\section{Acknowledgements}

We thank all participating sentinel general practitioners and their patients, as well as the epidemiologists and the laboratory teams who contributed to the study. This work was supported by European Commission Horizon 2020 programme [grant agreement No 634446].

\section{Conflict of interest}

None declared.

\section{Authors' contributions}

All authors contributed to development of the protocol. Ausenda Machado, Clara Mazagatos and Frederika Dijkstra coordinated the data gathering, analysis for each country and writing the first draft. Irina Kislaya, Alin Gherasim, Scott McDonald, Esther Kissling, Adam Meijer and Mariëtte Hooiveld contributed data gathering and analysis. Marta Valenciano, Baltazar Nunes and Amparo Larrauri coordinated the impact study. All authors contributed to interpretation and read and revised the final article.

\section{References}

1. Iuliano AD, Roguski KM, Chang HH, Muscatello DJ, Palekar $\mathrm{R}$, Tempia S, et al. Estimates of global seasonal influenza. associated respiratory mortality: a modelling study. Lancet. 2018;391(10127):1285-300. https://doi.org/10.1016/S01406736(17)33293-2 PMID: 29248255

2. Rolfes MA, Foppa IM, Garg S, Flannery B, Brammer L, Singleton JA, et al. Annual estimates of the burden of seasonal influenza in the United States: A tool for strengthening influenza surveillance and preparedness. Influenza Other Respir Viruses. 2018;12(1):132-7. https://doi.org/10.1111/irv.12486 PMID: 29446233

3. World Health Organization. Vaccines against influenza WHO position paper - November 2012. Wkly Epidemiol Rec. 2012;87(47):461-76. PMID: 23210147

4. World Health Organization (WHO). The Global Action Plan for influenza vaccines: report of the tenth meeting of the Advisory Group of the WHO Global Action Plan for Influenza Vaccines. Geneva: WHO; 2015. Available from: https://apps.who.int/iris/ handle/10665/182733

5. Mereckiene J, Cotter S, Nicoll A, Lopalco P, Noori T, Weber J, et al. Seasonal influenza immunisation in Europe. Overview of recommendations and vaccination coverage for three seasons: pre-pandemic (2008/09), pandemic (2009/10) and post-pandemic (2010/11). Euro Surveill. 2014;19(16):20780. https://doi.org/10.2807/1560-7917.ES2014.19.16.20780 PMID: 24786262

6. Jorgensen P, Mereckiene J, Cotter S, Johansen K, Tsolova S, Brown C. How close are countries of the WHO European Region to achieving the goal of vaccinating $75 \%$ of key risk groups against influenza? Results from national surveys on seasonal influenza vaccination programmes, $2008 / 2009$ to $2014 / 2015$. Vaccine. 2018;36(4):442-52. https://doi.org/10.1016/j. vaccine.2017.12.019 PMID: 29287683

7. Kissling E, Valenciano M, Buchholz U, Larrauri A, Cohen JM, Nunes B, et al. Influenza vaccine effectiveness estimates in Europe in a season with three influenza type/subtypes circulating: the I-MOVE multicentre case-control study, influenza season 2012/13. Euro Surveill. 2014;19(6):20701. https://doi.org/10.2807/1560-7917.ES2014.19.6.20701 PMID: 24556348

8. Valenciano M, Kissling E, Reuss A, Rizzo C, Gherasim A, Horváth JK, et al. Vaccine effectiveness in preventing laboratory-confirmed influenza in primary care patients in a season of co-circulation of influenza $A\left(\mathrm{H}_{1} \mathrm{~N}_{1}\right)$ pdmo9, $B$ and drifted $\mathrm{A}\left(\mathrm{H}_{3} \mathrm{~N}_{2}\right)$, I-MOVE Multicentre Case-Control Study, Europe 2014/15. Euro Surveill. 2016;21(7):30139. https://doi. org/10.2807/1560-7917.ES.2016.21.7.30139 PMID: 26924024

9. Foppa IM, Cheng P-Y, Reynolds SB, Shay DK, Carias C, Bresee JS, et al. Deaths averted by influenza vaccination in the U.S. during the seasons 2005/06 through 2013/14. Vaccine. 2015;33(26):3003-9. https://doi.org/10.1016/j. vaccine.2015.02.042 PMID: 25812842

10. Russell K, Chung JR, Monto AS, Martin ET, Belongia EA, McLean HQ, et al. Influenza vaccine effectiveness in older adults compared with younger adults over five seasons. Vaccine. 2018;36(10):1272-8. https://doi.org/10.1016/j. vaccine.2018.01.045 PMID: 29402578

11. Kostova D, Reed C, Finelli L, Cheng P-Y, Gargiullo PM, Shay DK, et al. Influenza illness and hospitalizations averted by influenza vaccination in the United States, 2005-2011. PLoS One. 2013;8(6):e66312. https://doi.org/10.1371/journal. pone.0066312 PMID: 23840439

12. Bonmarin I, Belchior E, Lévy-Bruhl D. Impact of influenza vaccination on mortality in the French elderly population during the 2000-2009 period. Vaccine. 2015;33(9):1099101. https://doi.org/10.1016/j.vaccine.2015.01.023 PMID: 25604800

13. Preaud E, Durand L, Macabeo B, Farkas N, Sloesen B, Palache $A$, et al. Annual public health and economic benefits of seasonal influenza vaccination: a European estimate. BMC Public Health. 2014;14(1):813. https://doi.org/10.1186/14712458-14-813 PMID: 25103091

14. Integrated Monitoring of Vaccines in Europe (I-MOVE+). Protocol for joint report on measuring the impact of influenza vaccination programmes among the elderly population in Spain, Navarra, the Netherlands and Portugal. Paris: Epiconcept; 2018. Available from: https://docs.google.com/ viewer? $\mathrm{a}=\mathrm{v} \& \mathrm{pid}=\mathrm{sites} \& \operatorname{srcid}=\mathrm{ZXBpY} 29 \mathrm{UY} 2 \mathrm{VwdC}$ mcn $x p b \mathrm{~W}_{92} \mathrm{Z}$ XBsdXN8Z3g6Njl1NWQ4MjBjZWFINzI3Yg

15. Teirlinck AC, de Gier B, Meijer A, Donker G, de Lange M, Koppeschaar $C$, et al. The incidence of symptomatic infection with influenza virus in the Netherlands 2011/2012 through $2016 / 2017$, estimated using Bayesian evidence synthesis. Epidemiol Infect. 2018;1-6. PMID: 30348244

16. Rodrigues AP, Fonseca RC, Matias-Dias C. Rede MédicosSentinela como Instrumento de Vigilância em Saúde. [General Practitioner Sentinel Network as a Tool of [Public] Health Surveillance]. Acta Med Port. 2016;29(1):5-9. Portuguese. https://doi.org/10.20344/amp.5938 PMID: 26926891

17. Larrauri Cámara A, Jiménez-Jorge S, Simón Méndez L, de Mateo Ontañón SSistema de Vigilancia de Gripe en España (SVGE). Vigilancia de la pandemia de gripe ( $\left.\mathrm{H}_{1} \mathrm{~N}_{1}\right) 2009$ en España. [Surveillance of influenza pandemic $\left(\mathrm{H}_{1} \mathrm{~N}_{1}\right) 2009$ in Spain]. Rev Esp Salud Publica. 2010;84(5):569-88. Spanish. PMID: 21203720

18. Donker G. NIVEL primary care database - sentinel practices 2015. Utrecht: Nivel; 2016. Available from: https://www.nivel. $\mathrm{nl} /$ sites/default/files/bestanden/Peilstations_2015_Engel.pdf

19. Heins M, Hooiveld M, Korevaar J. Vaccine coverage Dutch National influenza prevention program 2017: brief monitor. Utrecht: Nivel; 2018. Available from: https://www.nivel.nl/nl/ publicatie/vaccine-coverage-dutch-national-influenza-prevention-program-2017-brief-monitor

20. de Sanidad M, Consumo y Bienestar S, de España G. [Ministry of Health, Consumer Affairs and Social Welfare, Spanish Government]. Evolución de cobertura de vacunación antigripal en población $\geq 65$ años. España, temporadas 2009-2010 a 2018-2019. [Evolution of influenza vaccination coverage in the population $\geq 65$ years. Spain, seasons 2009-2010toa 20182019]. Madrid: Gobierno de España; 2018. Spanish. Available from: http://www.mscbs.gob.es/profesionales/saludPublica/ prevPromocion/vacunaciones/docs/CoberturasVacunacion/ Tabla4.pdf

21. Machado A, Kislaya I, Torres AR, Neto M. Vacinação antigripal da população portuguesa, em 2016/2017 e 2017/2018: cobertura e caracteristicas do ato vacinal. [Influenza vaccination of the Portuguese population, in 2016/17 and 2017/18: coverage and characteristics of the vaccination programme]. Lisbon: Instituto Nacional de Saude Doutor Ricardo Jorge, IP; 2018. Portuguese. Available from: http://repositorio.insa. pt/bitstream/10400.18/5700/3/INSA Relatorio Vacinacaoantigripal-epocas-2016-2017_2017-2018.pdf 
22. Kissling E, Valenciano M, Pozo F, Vilcu A-M, Reuss A, Rizzo C, et al. I-MOVE/I-MOVE+ study team. 2015/16 I-MOVE/I-MOVE+ multicentre case-control study in Europe: Moderate vaccine effectiveness estimates against influenza $A\left(\mathrm{H}_{1} \mathrm{~N}_{1}\right)$ pdmo9 and low estimates against lineage-mismatched influenza B among children. Influenza Other Respir Viruses. 2018;12(4):423-37. https://doi.org/10.1111/irv.12520 PMID: 29125681

23. Kissling E. Low vaccine effectiveness against influenza $\mathrm{A}\left(\mathrm{H}_{3} \mathrm{~N}_{2}\right)$ in Europe: Estimates from the I-MOVE multicentre case control study. European Scientific Conference on Applied Infectious Disease Epidemiology (ESCAIDE); 6-8 Nov 2017, Stockholm, Sweden.

24. Kissling E. 2017/18 European influenza season: Disparate I-MOVE multicentre case control study estimates with $A\left(\mathrm{H}_{1} \mathrm{~N}_{1}\right)$, $A\left(\mathrm{H}_{3} \mathrm{~N}_{2}\right)$ and trivalent vaccine lineage-mismatched $B /$ Yamagata influenza viruses circulating. European Scientific Conference on Applied Infectious Disease Epidemiology (ESCAIDE); 21-23 Nov 2018, Saint Julian's, Malta.

25. Caini S, Spreeuwenberg P, Kusznierz GF, Rudi IM, Owen R, Pennington K, et al. Distribution of influenza virus types by age using case-based global surveillance data from twentynine countries, 1999-2014. BMC Infect Dis. 2018;18(1):269. https://doi.org/10.1186/s12879-018-3181-y PMID: 29884140

26. Belongia EA, Simpson MD, King JP, Sundaram ME, Kelley NS, Osterholm MT, et al. Variable influenza vaccine effectiveness by subtype: a systematic review and meta-analysis of testnegative design studies. Lancet Infect Dis. 2016;16(8):94251. https://doi.org/10.1016/S1473-3099(16)00129-8 PMID: 27061888

27. Darvishian M, Dijkstra F, van Doorn E, Bijlsma MJ, Donker GA, de Lange MMA, et al. Influenza vaccine effectiveness in the Netherlands from 2003/2004 through 2013/2014: The importance of circulating influenza virus types and subtypes. PLoS One. 2017;12(1):e0169528. https://doi.org/10.1371/journal. pone.0169528 PMID: 28068386

28. Jackson ML, Phillips CH, Benoit J, Jackson LA, Gaglani M, Murthy K, et al. Burden of medically attended influenza infection and cases averted by vaccination - United States, 2013/14 through 2015/16 influenza seasons. Vaccine. 2018;36(4):46772. https://doi.org/10.1016/j.vaccine.2017.12.014 PMID: 29249545

29. Osterholm MT, Kelley NS, Sommer A, Belongia EA. Efficacy and effectiveness of influenza vaccines: a systematic review and meta-analysis. Lancet Infect Dis. 2012;12(1):36-44. https://doi. org/10.1016/S1473-3099(11)70295-X PMID: 22032844

30. Centers for Disease Control and Prevention (CDC). Estimated influenza illnesses and hospitalizations averted by influenza vaccination - United States, 2012-13 influenza season. MMWR Morb Mortal Wkly Rep. 2013;62(49):997-1000. PMID: 24336131

31. Centers for Disease Control and Prevention (CDC). 2016-2017 estimated influenza illnesses, medical visits, and hospitalizations averted by vaccination in the United States. Atlanta: CDC; 2018. Available from: https://www.cdc.gov/flu/about/ disease/2016-17.htm

32. Oliva J, Delgado-Sanz C, Larrauri ASpanish Influenza Surveillance System. Estimating the burden of seasonal influenza in Spain from surveillance of mild and severe influenza disease, 2010-2016. Influenza Other Respir Viruses. 2018;12(1):161-70. https://doi.org/10.1111/irv.12499 PMID: 28960828

33. Peppa M, John Edmunds W, Funk S. Disease severity determines health-seeking behaviour amongst individuals with influenza-like illness in an internet-based cohort. BMC Infect Dis. 2017;17(1):238. https://doi.org/10.1186/s12879-017-23375 PMID: 28359335

34. Ma W, Huo X, Zhou M. The healthcare seeking rate of individuals with influenza like illness: a meta-analysis. Infect Dis (Lond). 2018;50(10):728-35. https://doi.org/10.1080/23744235 .2018.1472805 PMID: 30009680

35. World Health Organization (WHO). Outpatient contacts per person per year. European Health for All database (HFA-DB). Geneva: WHO. [Accessed: 6 Dec 2018]. Available from: https://gateway.euro.who.int/en/indicators/ hfa_543-6300-outpatient-contacts-per-person-per-year/

36. de Almeida Simões J, Augusto GF, Fronteira I, HernándezQuevedo C. Portugal: health system review. Health Syst Transit. 2017;19(2):1-184. PMID: 28485714

37. Bernal-Delgado E, Garcia-Armesto S, Oliva J, Sanchez Martinez FI, Repullo JR, Pena-Longobardo LM, et al. Spain: health system review. Health Syst Transit. 2018;20(2):1-179. PMID: 30277216

38. Kroneman M, Boerma W, van den Berg M, Groenewegen P, de Jong J, van Ginneken E. Netherlands: health system review. Health Syst Transit. 2016;18(2):1-240. PMID: 27467715

39. Eichner M, Schwehm M, Eichner L, Gerlier L. Direct and indirect effects of influenza vaccination. BMC Infect Dis.
2017;17(1):308. https://doi.org/10.1186/s12879-017-2399-4 PMID: 28441935

40. Backer JA, Wallinga J, Meijer A, Donker GA, van der Hoek W, van Boven $M$. The impact of influenza vaccination on infection, hospitalisation and mortality in the Netherlands between 2003 and 2015. Epidemics. 2019;26:77-85. https://doi. org/10.1016/j.epidem.2018.10.001 PMID: 30344024

41. Yin JK, Heywood AE, Georgousakis M, King C, Chiu C, Isaacs D, et al. Systematic review and meta-analysis of indirect protection afforded by vaccinating children against seasonal influenza: Implications for policy. Clin Infect Dis. 2017;65(5):719-28. https://doi.org/10.1093/cid/cix420 PMID: 28475770

42. Pel JZS. (Pilot study of the frequency and aetiology of influenza-like illness in winter 1963-1964). Proefonderzoek naar de frequentie en de aetiologie van griepachtige ziekten in de winter 1963-1964. Huisarts Wet. 1965;86:321.

43. European Commission. Commission Implementing Decision 2012/506/EU of 8 August 2012 amending Decision 2002/253/ EC laying down case definitions for reporting communicable diseases to the Community network under Decision No 2119/98/EC of the European Parliament and of the Council. Official Journal of the European Union. 2012;55(3):L262/1-57. Available from: https://op.europa.eu/en/publicationdetail/-/publication/10ed46of-0711-11e2-8e28-01aa75ed71a1/ language-en

\section{License, supplementary material and copyright}

This is an open-access article distributed under the terms of the Creative Commons Attribution (CC BY 4.0) Licence. You may share and adapt the material, but must give appropriate credit to the source, provide a link to the licence and indicate if changes were made.

Any supplementary material referenced in the article can be found in the online version.

This article is copyright of the authors or their affiliated institutions, 2019. 